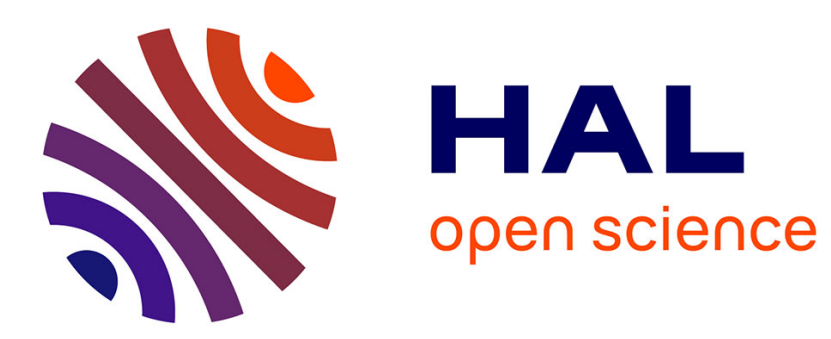

\title{
PHOTO INDUCED INFRARED ACTIVE PHONONS IN TRANS POLYACETYLENE
}

Z. Vardeny, J. Orenstein, G. Baker

\section{To cite this version:}

Z. Vardeny, J. Orenstein, G. Baker. PHOTO INDUCED INFRARED ACTIVE PHONONS IN TRANS POLYACETYLENE. Journal de Physique Colloques, 1983, 44 (C3), pp.C3-325-C3-328. 10.1051/jphyscol:1983364 . jpa-00222716

\section{HAL Id: jpa-00222716 https://hal.science/jpa-00222716}

Submitted on 1 Jan 1983

HAL is a multi-disciplinary open access archive for the deposit and dissemination of scientific research documents, whether they are published or not. The documents may come from teaching and research institutions in France or abroad, or from public or private research centers.
L'archive ouverte pluridisciplinaire HAL, est destinée au dépôt et à la diffusion de documents scientifiques de niveau recherche, publiés ou non, émanant des établissements d'enseignement et de recherche français ou étrangers, des laboratoires publics ou privés. 


\title{
PHOTO INDUCED INFRARED ACTIVE PHONONS IN TRANS POLYACETYLENE
}

\author{
Z. Vardeny*, J. Orenstein ${ }^{* *}$ and G.L. Baker** \\ * Physics Department, Technion-Israel Institute of Technology, Haifa 32000 , \\ Israel \\ **Bell Laboratories, Murray Hill, N.J. 07974, U.S.A.
}

\begin{abstract}
Rêsumé - Nous avons mis en évidence des phonons actifs dans 1 'infrarouge dans le trans ( $\mathrm{CH})$ par une technique d'absorption photoinduite. Il y a une corrélation avếc une bande d'absorption photoinduite d'origine électronique. Nos résultats montrent la photoproduction de défauts libres chargés avec un temps de vie long.
\end{abstract}

Abstract - We measured photogenerated ir active phonons in trans-(CH) by the photoinduced absorption technique. A correlation was found to exist with a photoinduced absorption band in which electronic transitions are involved. Our results show photoproduction of free charged defects with long lifetimes.

In the photoinduced optical absorption technique (PA), the signal arises from the change $\Delta \alpha$ in the optical absorption spectrum of the semiconductor due to the presence of excited carriers. Recently, Orenstein and Baker have reported measurements of the PA spectrum in $(\mathrm{CH})$ at a delay time of $10 \mu \mathrm{sec}$ following excitation, in the energy range $0.5 \mathrm{eV}$ to $1.6 \mathrm{eV}$. In trans - (cH) they observed two new subgap PA bands at $1.36 \mathrm{eV}$ and at $0.5 \mathrm{eV}$. These bands appear to be uncorrelated to each other due to their different decay time and different
temperature dependence. Very recently the resultant interband bleaching at $2 \mathrm{eV}^{3}$ and the PA spectrum from $1.2 \mathrm{eV}$ to $1.9 \mathrm{eV}^{4}$ were measured with picosecond pulse excitation. It was shown that the gap states and their resultant interband bleaching are produced in less then $10^{-13}$ sec and that the photogenerated carriers are localized but highly mobile ${ }^{3}$.

In this work we report the steady state PA spectrum in txans (CH) ip the energy range 0.09 to $1.1 \mathrm{ev}$, which includes also the phonons energy range 5 . The photoinduced changes in the sample optical absorption spectrum were measured with an incandescent light source dispersed by a monochromator. The light transmitted through the sample $(T)$ and its changes $(\Delta T)$ were measured with a solid state detector having a wide spectral range. The laser beam used for excitation was a $\mathrm{CW} \mathrm{Ar}{ }^{+}$with photon energy of $2.4 \mathrm{eV}$ which is larger than the gap of trans- $(\mathrm{CH})$. Phase detection techniques improved the sensitivity of $\Delta T / T$ to $10^{-5} \frac{\text { for most }}{\text { parts }}$ of the spectrum. The sample was in the form of thin film of (CH) grown on $\mathrm{NaCl}$ substrate, initially polymerised as $\underline{\mathrm{cis}-(\mathrm{CH})} \mathrm{x}$ and subsequently isomerized to trans${ }^{(\mathrm{CH})} \mathrm{x}^{\cdot}$

In Fig. 1 the induced absorption $(-\Delta T / T)$ at $10 \mathrm{~K}$ obtained with a laser absorbed power of $20 \mathrm{mwam}^{-2}$ is plotted versus the probe photon energy. The PA spectrum consists of an assymetric band peaked at $0.43 \mathrm{eV}$ with a FWHM of $0.35 \mathrm{eV}$ and a mugh narrower doubly peaked feature with maxima at $170 \mathrm{meV}\left(1360 \mathrm{~cm}^{-1}\right)$, and $157 \mathrm{meV}\left(1256 \mathrm{~cm}^{-1}\right.$ ) with FWHM of less than $4 \mathrm{meV}\left(32 \mathrm{~cm}^{-1}\right)$. At higher temperatures these bands decrease in intensity and shift up in energy $(172 \mathrm{meV}$ and $0.48 \mathrm{eV}$ at $200 \mathrm{~K})$. We identify the narrow $\mathrm{PA}_{5}$ bands as induced ir active phonons, due to their energy location ${ }^{6}$ and sharpness 5 . The broader assymetric PA band is due to electron transitions from photoinduced localized states in the gap (with a delta function energy distribution) 


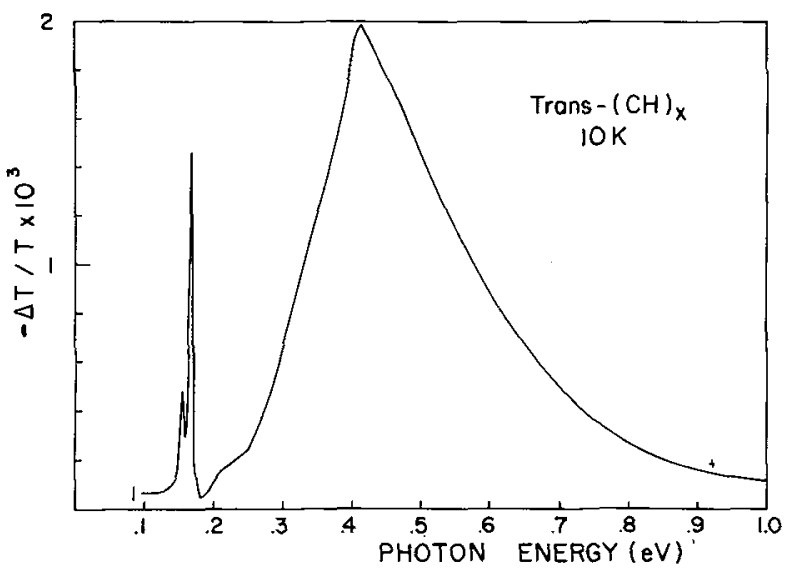

to the nearest band edges (with an almost square root singularity in a quazi iD system like (CH) However we note that this band is sharper than half the width of the interband absorption of trans(CH) (which is about $1 . \overline{5 e V}$ ). The lack of induced bleaching $(\Delta \alpha<0)$ in the whole energy range below the gap shows that the induced localized states cannot be associated with ionization of ingap natural impurities. Also the lack of induced bleaching in the energy range of the natural ir active 9 phonons located in trans- $(\mathrm{CH}) \mathrm{x}$ at $1015 \mathrm{~cm}^{-1}$ and at $3000 \mathrm{~cm}^{-1 x}$,

Fig. 1 - Photoinduced absorption spectrum. $\Delta \alpha=2.5 \times 10^{5} \Delta \mathrm{T} / \mathrm{T}$.

shows that the photoinduced phonons to not take their large oscillator strength from the C-H vibrations. Both PA bands (the electronic and the vibronic) derive their strength directly from the $\pi-\pi^{*}$ transitions. In fact we observed (not shown in $F i g$. 1), photoinduced bleaching for hw above $E$ which we could associate with the appearange of the new PA bands. This proves that these bands are intrinsic in origin $^{2-4}$.

The PA bands at $0.43 \mathrm{eV}$ and at $0.15-0.17 \mathrm{eV}$ share a common origin since their absorption strength $\Delta \alpha(=\alpha, \Delta \mathrm{T} / \mathrm{T}, \alpha$ is the absorption coefficient at the laser frequency) exhibits simjlar dependencies on the laser intensity, laser chopper frequency and sample temperature. An example is shown in Fig. 2 where their intensities at $80 \mathrm{~K}$ are plotted as a function of the laser chopping frequency; the PA strength for each lines saturatesat about $200 \mathrm{~Hz}$. Since $\Delta \alpha=N$ o (where $N$ is the steady state density and $\sigma$ is the defect absorption cross-section), this srequency dependence shows that steady state condition is reached on $7 y$ at about $5 \times 10^{-3}$ sec, implying that the recombination lifetime is longer than $10^{-3}$ sec at $80 \mathrm{~K}$. We measured the dependence of $\Delta \alpha$ on the laser intensity-I (Fig.3). $\Delta \alpha$ for both bands has a $I^{\frac{1}{2}}$ behaviour, characteristic of bimolecular recombination kinetics, followed by saturation at high intensities. The PA strength for both bands decreases with

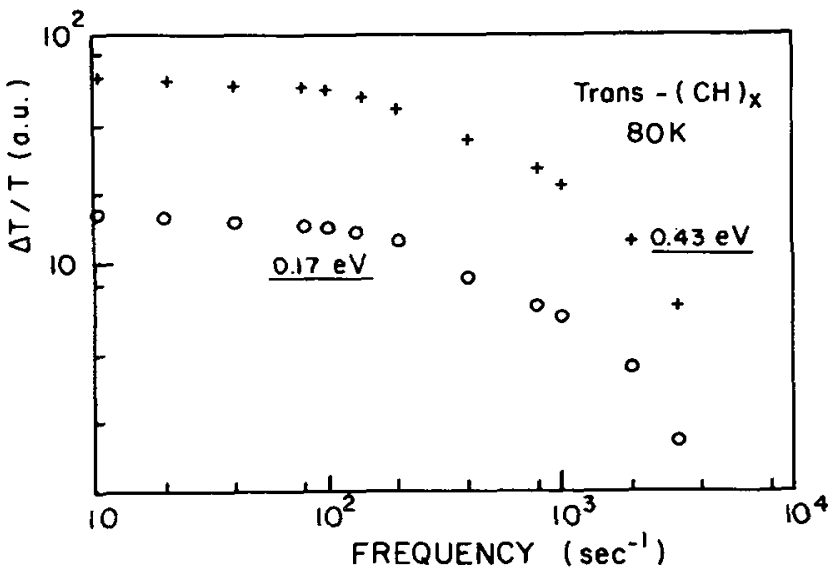

Elg. 2 - The dependence of $\Delta T^{\prime} / T$ on the laser chopping frequency. temperature: a slow decrease up to $150 \mathrm{~K}$, where the decrease becomes more pronounced. We conclude therefore that the electronic and the vibronic PA are due to the same photoinduced defects.

We can estimate $\mathrm{N}$ shown in Fig. 1 assuming that the doping induced and the photoinduced defects have similar $\Sigma$. From the doping induceg "midgap" absorption band and the associated impurity density we evaluate the defect integrated absorption crgsssection $\Sigma=\int \sigma d E \simeq 4 \times 10^{-16} \mathrm{~cm}^{2} \mathrm{eV}$.

Integrating the $0.43 \mathrm{eV}$ absorption in Pig. 1, we 


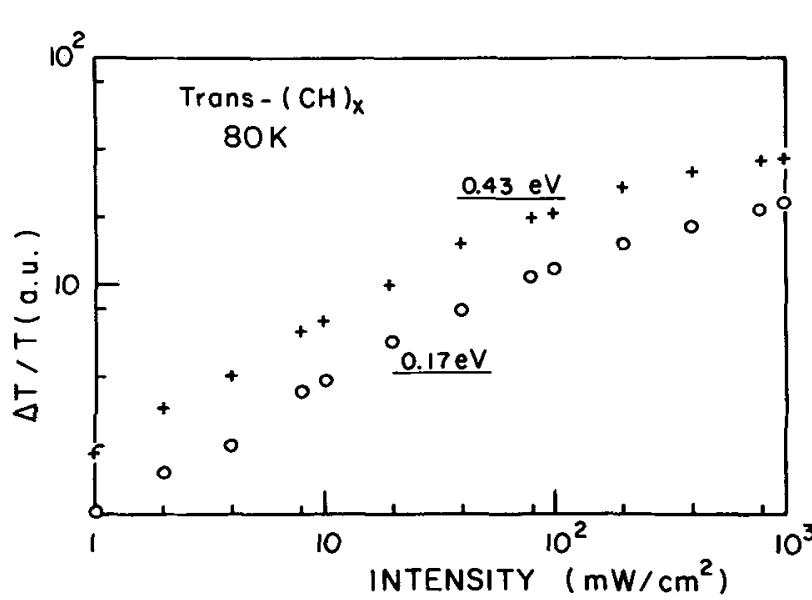

Fig. 3 - The dependence of $\Delta T / T$ at $80 \mathrm{~K}$ on the laser intensity-I calculate $\mathrm{N} \simeq 6 \times 10^{17} \mathrm{~cm}^{-3}$. From this we can estimate the generation quantum efficiency $i_{i}$ of these defects, since $\mathrm{N}_{5}=$ Gnt. Taking $\tau \approx 5 \times 10^{-3} \mathrm{sec}, \eta^{\mathrm{s}}$ is of order $10^{-2}$. This $\eta$ is consistent with the decay in the picosecond time range which was interpreted as due to geminate recombination ${ }^{4}$ the induced signal in trans- $(\mathrm{CH})$ decays to $5 \times 10^{-2}$ of its $x$ strength at $t=0$ in $1.5 \times 10^{-9} \mathrm{sec}$ at $80 \mathrm{~K}^{3}$.

The infrared activity in the phonon range in both photoinduced and doping induced cases ${ }^{\circ}$, proves that the induced defects are charged. However there is an important difference between the induced

spectra in the phonon range obtained by the two different methods. In the earlier work two strong ir active phonons were observed upon dilute doping in trans-(CH) : a narrow $\left(50 \mathrm{~cm}^{-1}\right)$ mode at $1370 \mathrm{~cm}^{-1}$ and a broader $\left(300 \mathrm{~cm}^{-1}\right)$ mode at $900 \mathrm{~cm}$. In more recent experiments $1^{10}$ third weaker vibration was observed at $1270 \mathrm{~cm}^{-1}$. In the case of photogeneration we observe only $\underline{1}_{1}$ the two high frequency vibrations (slightly shifted at $10 \mathrm{~K}$ ), namely at $1360 \mathrm{~cm}^{-1}$ and at $1255 \mathrm{~cm}$. The $900 \mathrm{~cm}^{-1}$ mode is completely missing from the PA spectrum (see Fig. 1). In their original work', Su, Schrieffer and Heeger interpreted the doping induced ir active vibrations as due to charged soliton vibrations. However the lower frequency mode at $900 \mathrm{~cm}^{-1}$ was ascribed to vibrations of the soliton against the impurity, and therefore it is a pinned modg;7 Later, some contraversy about the origin of this mode appeared in the literature $5 ; 7$. In our case the photoinduced defects are not connected to impurities and therefore should not be pinned. The failure to observe this mode in the photoinguced experiment confirms therefore that the $900 \mathrm{~cm}^{-1}$ mode is indeed the pinned mode 7 ,

Based on B. Horovitz general analysis ${ }^{7}$, we can tentatively associate each new ir active mode to phonons lines of $\mathrm{C}=\mathrm{C}$ stretch character which are observed in $\mathrm{Raman}$ scattering. The $1360 \mathrm{~cm}^{-1}$ line is the modifed $1470 \mathrm{~cm}^{-1} \mathrm{C}=\mathrm{C}$ mode , the $1255 \mathrm{~cm}^{-1}$ is the modified $1290 \mathrm{~cm}^{-1} \mathrm{C}-\mathrm{C}$ mode ${ }^{5}$ (which appears weaker in Raman scattering) and the strong $1090 \mathrm{~cm}^{-1}$ mode observed in Raman scattering is shifted to frequency lower than $750 \mathrm{~cm}^{-1}$ (our experimental lower limit) and is transformed into the pinned mode of the free defect which theoretically is shifted to $\omega=0$.

Based on our calculation of $\mathrm{N}$ we can estimate the defect mass (a more precise calculation which is not based on $\mathrm{N}$ will be published elsewhere). The induced absorption strength $\Delta \alpha$ at $0.17 \mathrm{eV}$ is about $350 \mathrm{~cm}^{-1}$; similar in strength to the absorption of the natural ir active phonons of trans - $(\mathrm{CH})$. Taking $\mathrm{N}_{\mathrm{s}}=6 \times 10^{\mathrm{cm}} \mathrm{cm}^{-3}$, the oscillator strength per induced defect is enhanced by more than 3 order of magnitudes as compared to the natural vibrations of this compound. A defect (or impurity) mode ir oscillator strength is inversly proportional to its vibrating mass; ${ }^{2}$ we conclude therefore that the defect mass should be of order of $\mathrm{m}$ (electron mass).

Our results show that supergap light absorption in trans-(CH) produces mobile, light mass charged defects with associated ingap localized states, whose lifetime is longer than few miliseconds. These findings may show indeed that free charged solitons are photogenerated in trans-(CH) 3 since they fit the expected soliton properties. However there are yet two unresolved problems in this picture 
connected with our findings: (i) The electronic PA band is located at $0.43 \mathrm{eV}$ (with threshold at $0.25 \mathrm{ev})$, quite far from the expected soliton absorption at midgap(0.7 eV). (ii) The PA strength saturates at high light intensities; we estimate the saturation defect density to be $2-4 \times 10^{18} \mathrm{~cm}^{-3}$. Solitons possess a reverse chargespin relationship and it was theoretically shown that photoinduced e-h pair decays to charged soliton-antisoliton pair (J.R. Schrieffer, Les Arc conference). since our experiment definitely shows the existence of photoinduced charged defects, the crucial experiment needed now to prove solitons photogeneration in trans-(CH) is to measure the unpaired spins photogeneration quantum efficiency. However the saturation at high illumination intensities and the small charged defects quantum efficiency certainly influence the conclusions of this crucial experiment. Preliminary results where these effects were taken into consideration (A. Heeger, Les Arc conference) suggest that this quantum efficiency is indeed smali.

on the other hand our results might fit photoproduction of charged polarons. The energy threshold of the electronic PA at $0.25 \mathrm{eV} f 15,16$ well the predicted low energy transition of the charged polaron in trans- $(\mathrm{CH}){ }^{15,16}$. However a second correlated transitiop at higher energy $(1.1$ to $1.4 \mathrm{eV})$, which was also predicted for charged polarons ${ }^{15}$ was not found in the PA experiments (J. Orenstein et.al., Les Arc conference).

A part of this work was done at Brown University while one of us ( $Z . V$. ) was supported by the NSF MRL program and by NSF Grant; we thank Prof. J. Tauc for his kindly support, T. Kirst and D. Pfost for technical assistance and $B$. Horovitz for fruitful discussions.

\section{References}

1. O'connor P. and Tauc J., Phys. Rev. B25 (1982) 2748.

2. Orenstein $J$. and Baker G.L., Phys. Rev. Lett. 49(1982) 1043.

3. Vardeny Z., Strait J., Moses D., Chung T.C. and Heeger A.J. Phys. Rev. Lett. 49 (1982) 1657.

4. Shank C.V., Yen R., Fork R.L., Orenstein J. and Baker G.L., Phys. Rev. Lett. 49 (1982) 1660 .

5. Kuzmany H., Phys. Stat. Sol. (b) $97(1980) 521$.

6. Etemad S., Pron A., Heeger A.J., MacDiarmid A.G., Mele E.J. and Rice M.J., Phys. Rev. B23(1981) 5137.

7. Horovitz B., Sol. State Commun. 41 (1982) 729.

8. Feldblum A., Kaufman J.H., Etemad̆ S., Heeger A.J., Chung T.C. and MacDiarmid A.G., Phys. Rev. B26 (1982)815.

9. Shirakawa H. and I keda S., Polym. Jour. 2 (1971) 231.

10. Tanaka M., Fujimoto $\mathrm{H}$. and Tanaka J., MoI. Cryst. Liq. Cryst. 83 (1981) 75; Kiess H., Baeriswyl D. and Harbeke G. Ibid 77 (1981) 147.

11. Su. W.P., Schrieffer J.R. and Heeger A.J. Phys. Rev. Lett. 42 (1979) 1698; Phys. Rev. B22 (1980) 2099.

12. Barker A.S.Jx. and Sievers A.J., Review of Modern Physics, 47(1975) 2 .

13. Su. W.P. and Schrieffer J.R., Proc. Nat. Acad. Sci. USA 77 (1980) 5626.

14. Lauchlan L., Etemad S., Chung T.C. Heeger A.J. and MacDiarmid A.G., Phys. Rev. B24 (1981) 1 .

15. Bishop A.R., CampbeII D.K. and Fesser K., Mol.Cryst. Liq. Cryst. 77 (1981) 253 .

16. Brazovskii S. and Kirova N. JETP Lett. 33 (1981)4. 